Title:

\title{
TEMPERA'TURE LOWERING IN CRYOGENIC CHEMICAL-SYNTHESIS TECHNIQUES AND SYSTEM
}

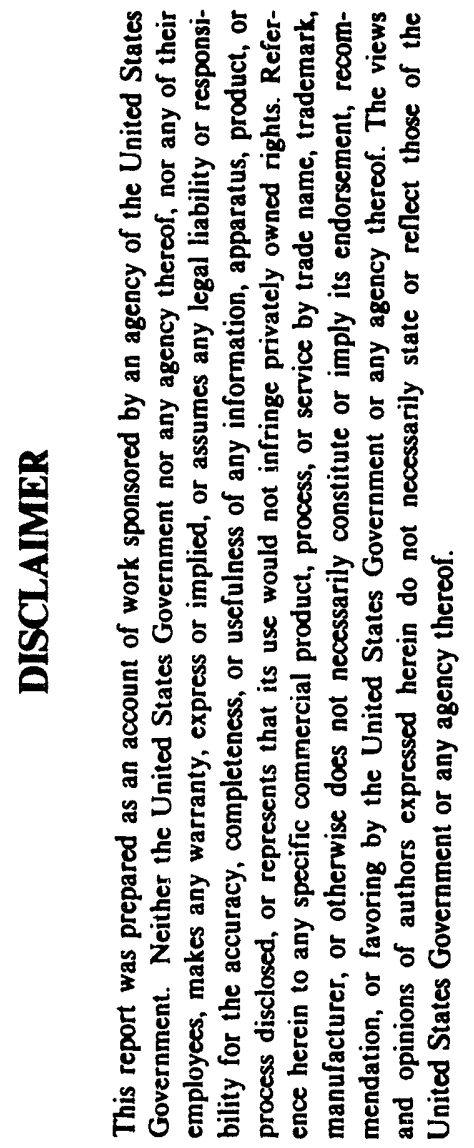

Cryogenic Engineering Conference

July 12-16, 1993

Albuquerque, NM

H. E. Martinez, MEE-9

T. O. Nelson, NMT-6

L. N. Vikdal, MEE-9

Author(s)

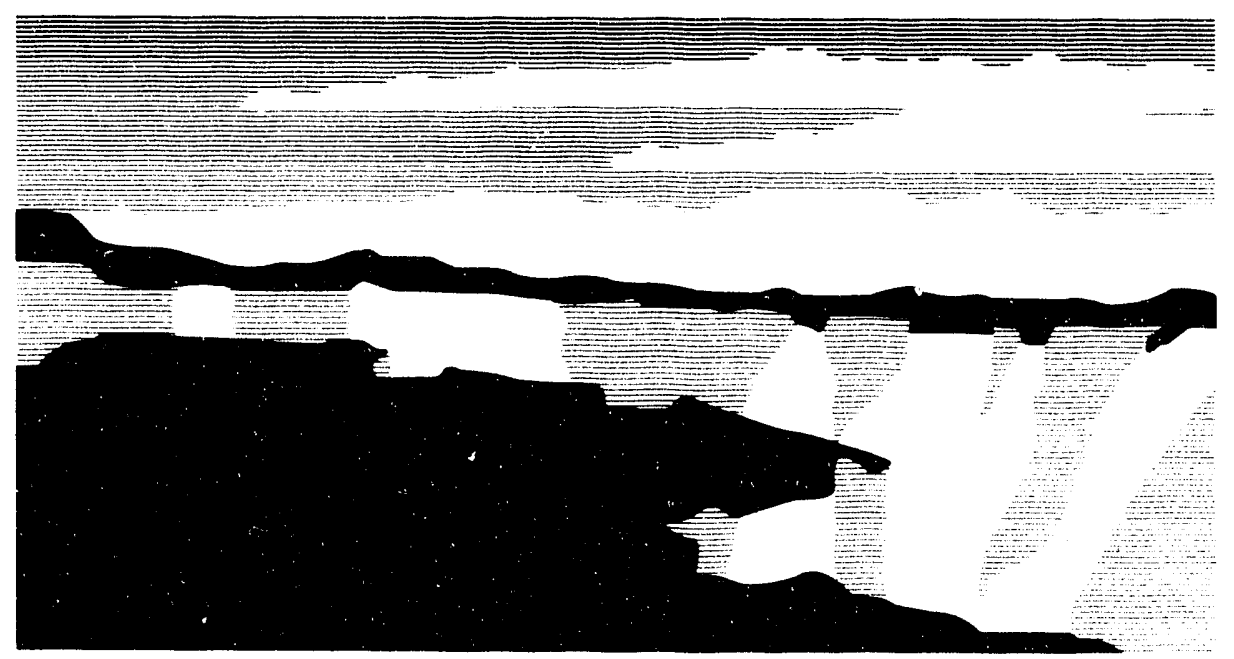

Los Alamos National Laboratory, an affirmative action/equal opportunity employer, is operated by the University of California for the U.S. Department of Energy under contract W-7405-ENG-36. By acceptance of this article, the publisher recognizes that the U.S. Gevernment retains a nonexclusive, royalty-free license to publish or reproduce the published form of this contribution, or to allow others to do so, for U.S. Government purposes. The Los Alamos National Laboratory requests that the publisher identity this articie as work fertormed under the auspices of the U.S. Department of Energy. 


\title{
TEMPERATURE LOWERING IN CRYOGENIC CHEMICAL-SYNTHESIS TECHNIQUES AND SYSTEM
}

\author{
H. E. Martinez, T. O. Nelson, and L. N. Vikdal \\ Los Alamos National Laboratory, \\ Los Alamos, New Mexico, 87545, U.S.A.
}

\begin{abstract}
When evaluating a chemical synthesis process for a reaction that occurs on the cryogenically cooled walls, it is sometimes necessary to reduce the wall temperatures to enhance the chemical process. To evaluate the chemical process at lower than atmospheric boiling of liquid nitrogen, we built a system and used it to reduce the temperature of the liquid nitrogen. The technique of lowering the liquid nitrogen temperature by reducing the pressure of the boil-off is established knowledge. This paper presents the engineering aspects of the system, design features, equipment requirements, methods of control, and results of the chemical synthesis. The heat input to the system was $\approx 400$ watts, placing a relatively large demand on the pumping system. Our system is a scale-up of the small laboratory experiment, and it provides the information needed to design an effective system. The major problem encountered was the large quantity of liquid escaping the system during the processing, placing a large gas load on the vacuum system.
\end{abstract}

\section{INTRODUCTION}

A chemical production system that synthesizes an F-atom donor compound, krypton difluoride $\left(\mathrm{KrF}_{2}\right)$, uses liquid nitrogen as a coolant to provide a cold wall for the chemical production to occur. Gas-solid synthesis of $\mathrm{KrF}_{2}$ occurs according to the following chemical processes:

$$
\begin{aligned}
& \mathrm{F}_{2} \stackrel{\text { heat }}{-\cdots-->} 2 \mathrm{~F} \\
& \text { cold wall } \\
& \mathrm{F}+\mathrm{Kr} \\
& \text { cold wall } \\
& \mathrm{KrF}+\mathrm{F}-\mathrm{CrF}_{2} \text { (stable at liquid nitrogen temperature) }
\end{aligned}
$$

In the first step, molecules of fluorine are heated to about $950 \mathrm{~K}$ causing dissociation into atoms. Additionally, Krypton is attracted to the cold $(78 \mathrm{~K})$ outside wall, of the synthesis reactor by condensation, resulting in a $\mathrm{Kr}$ vapor pressure of a few torr. At the temperature of the cold wall reactor surface, the krypton and a single fluorine atom can form the thermally unstable intermediate compound, KrF. Subsequently, another fluorine atom can attach itself to the unstable $\mathrm{KrF}$ molecule on the cold wall to form the more stable $\mathrm{KrF}_{2}$ molecule. 
Our experiments were designed to increase the production rate of $\mathrm{KrF}_{2}$ by lowering the cold wall temperature below $78 \mathrm{~K}$. Reducing the temperature by a few degrees would increase the stability of the $\mathrm{KrF}$ intermediate, as well as reduce the amount of krypton in the gas phase. We used the standard method of reducing atmospheric liquid nitrogen temperature by reducing the vapor pressure of the boil off of the liquid nitrogen. ${ }^{1}$ It has been estimated that reducing the cold wall temperature by $10 \mathrm{~K}$ would increase the production rate by a factor of six. ${ }^{2}$ To lower the $\mathrm{LN}_{2}$ vapor pressure, the original synthesis reactor was modified by adding a sealed container-Dewar, a ballast tank, and a pumping system. ${ }^{3}$

This paper describes the engineering aspect of the system and the information that would help in designing and controlling a process that requires lowering the liquid nitrogen vapor pressure. The main engineering constraint comes from the heat load of the system, approximately 500 watts, which includes heat loads from the environment. This heat load is removed by the phase change of the $\mathrm{LN}_{2}$ and the gas temperature rise to ambient, which produces large pumping requirements, 5200 torr-L/s. Additionally, an accurate reactor temperature was calculated by heat transfer analysis, showing that the actual temperature for synthesis is larger than expected.

\section{EXPERIMENTAL METHOD}

The reaction vessel is contained within a sealed, insulated liquid-nitrogen container that serves as the cooling source for the reaction vessel. The experimental test setup is shown in Figure 1. A heat load of 400 watts comes from a hot nickel wire filament within the reaction vessel; the filament is at about $950 \mathrm{~K}$. An electrical power supply provides dc power to the nickel wire filament, and the temperature is controlled based on prior calibration of the filament. (The hot nickel wire is the catalyst used to disassociate fluorine molecules into atoms, reaction 1). Liquid nitrogen from a $1700 \mathrm{~L}$ Dewar outside the experimental laboratory flows into the liquid nitrogen container. The contain. is vented to the atmosphere or routed to a large evacuated ballast tank $(1400 \mathrm{~L})$ that is pumped by several large vane pumps, which have a total pumping capacity of about $80 \mathrm{~L} / \mathrm{s}(170 \mathrm{cubic} \mathrm{ft} / \mathrm{min})$, the performance of the vacuum pumps system is shown in Figure 2.

The chemical processing loop is a closed system with a mixture of fluorine and krypton that is circulated through the reaction vessel at closely controlled conditions (see Figure 1). Pressure and temperature were monitored using data acquisition that consisted of an HP 3852A scanner, a Macintosh IIfx computer, and Lab View software from National Instruments. Figure 3 shows the instrumentation and data-gathering system in the test setup of the reaction vessel and liquid nitrogen cooling container.

\section{PROCEDURE}

To perform the synthesis, the processing loop is loaded with an initial mixture of fluorine and krypton. The gas mixture is circulated through the reaction vessel, the dc power to the filament is started, and the flow of liquid nitrogen is initiated, venting the nitrogen gas to atmosphere. The heater power was adjusted to bring the filament temperature to the desired level, and the liquid nitrogen flow rate was manually regulated so the thermocouples on the outside of the reaction vessel indicated that the wall of the reactor was submerged and cooled by liquid nitrogen. Too much flow was indicated by liquid coming out of the vent tube. When the system reached steady state, a small steady flow of krypton gas was injected into the reactor; thus, condensing $\mathrm{Kr}$ on the wall provided a fresh surface for the chemical reaction to occur.

Many baseline production runs were performed using atmospheric pressure boil-off of the liquid nitrogen. When the experimentation and production of krypton difluoride was performed with the liquid nitrogen at a lower pressure, the valve from the evacuated ballast tanks to the pumping system was opened and the vent valve was closed. As the nitrogen pressure in the vessel began to drop, both the liquid nitrogen flow rate and the power to the filaments were adjusted to maintain the desired condition in the reaction vessel. The flow of liquid nitrogen was manually adjusted until the system reached a steady-state temperature on the walls of the reactor vessel. 


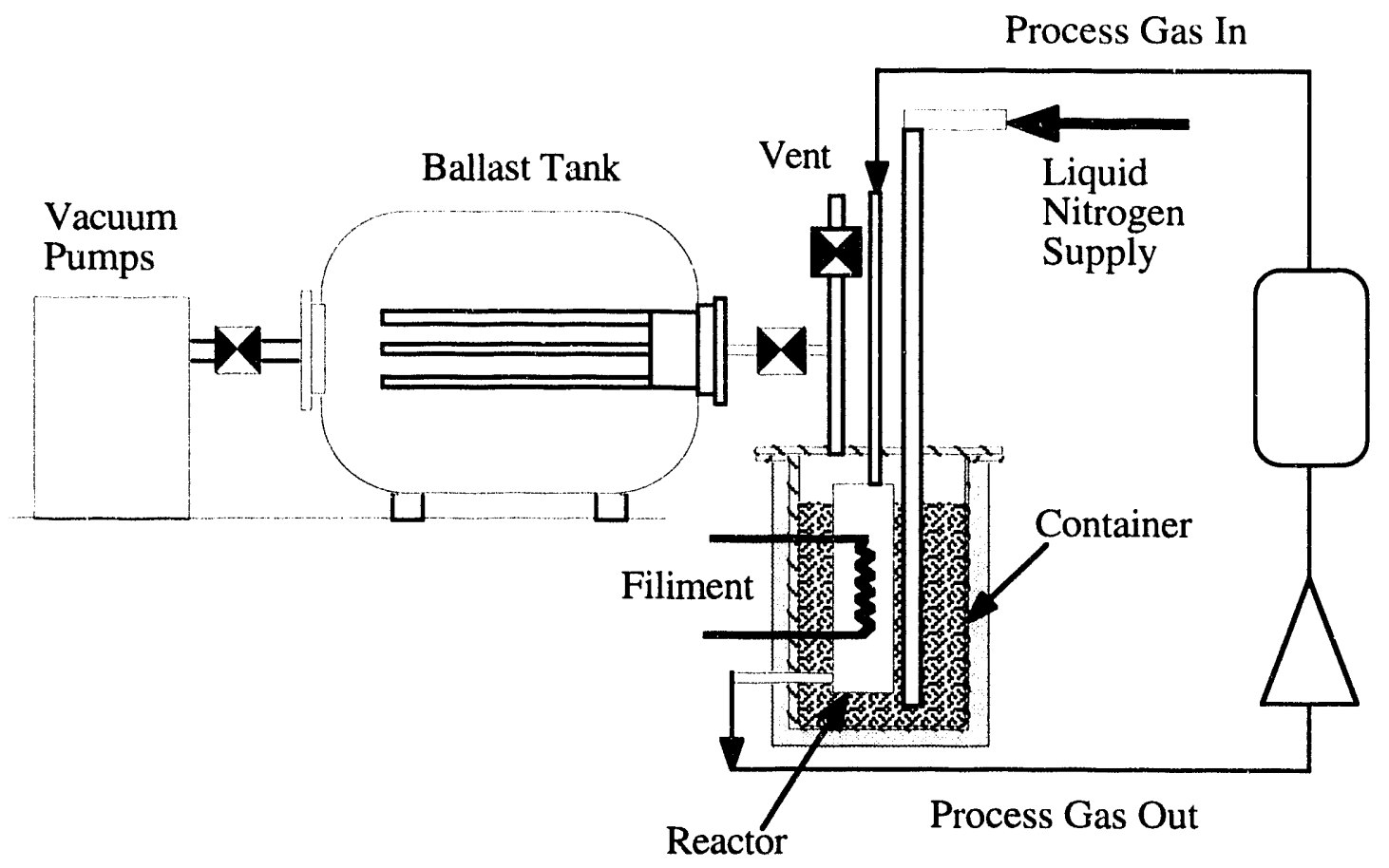

Figure 1. Experimental test setup.

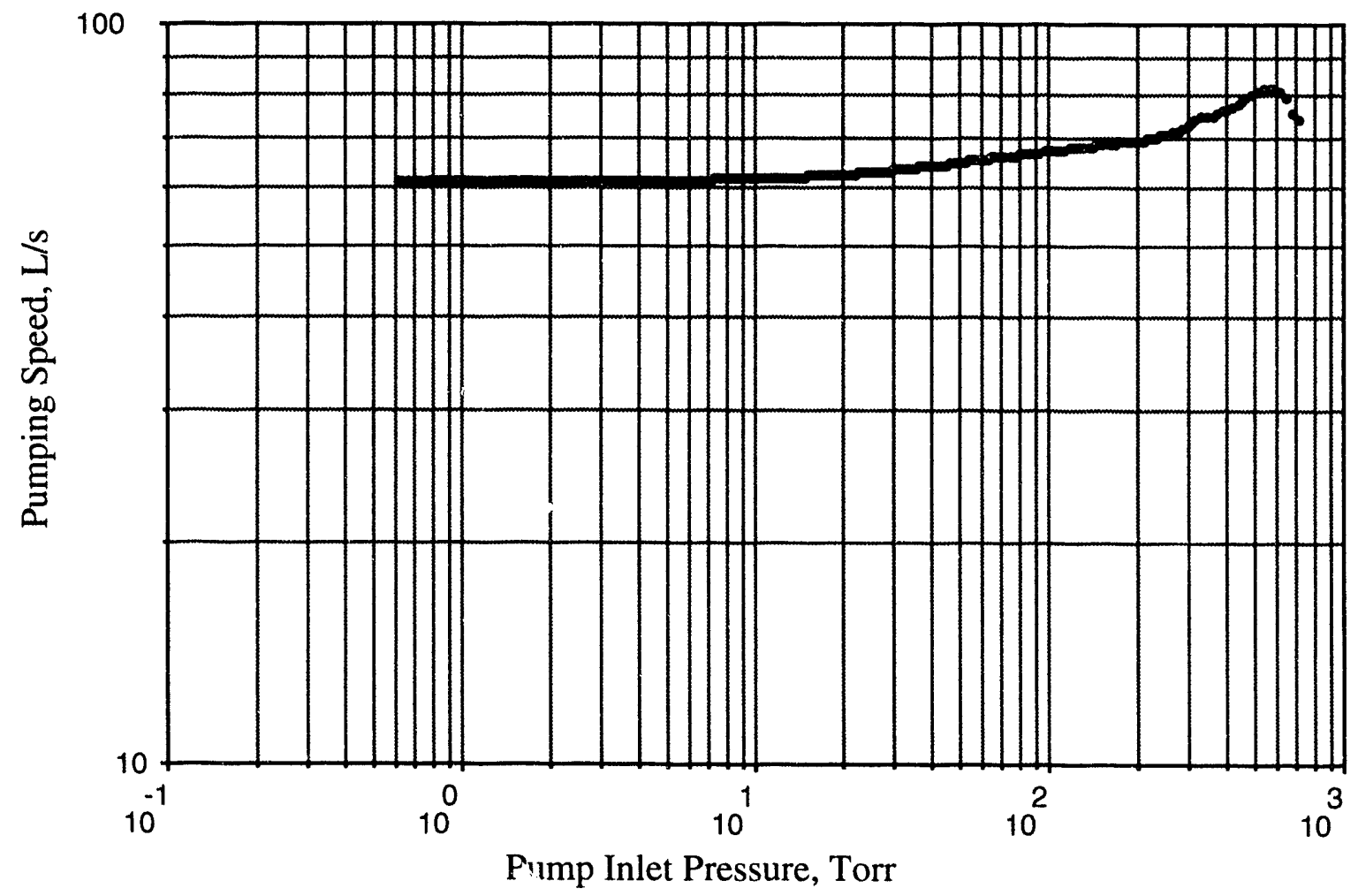

Figure 2. Vacuum pump performance. 


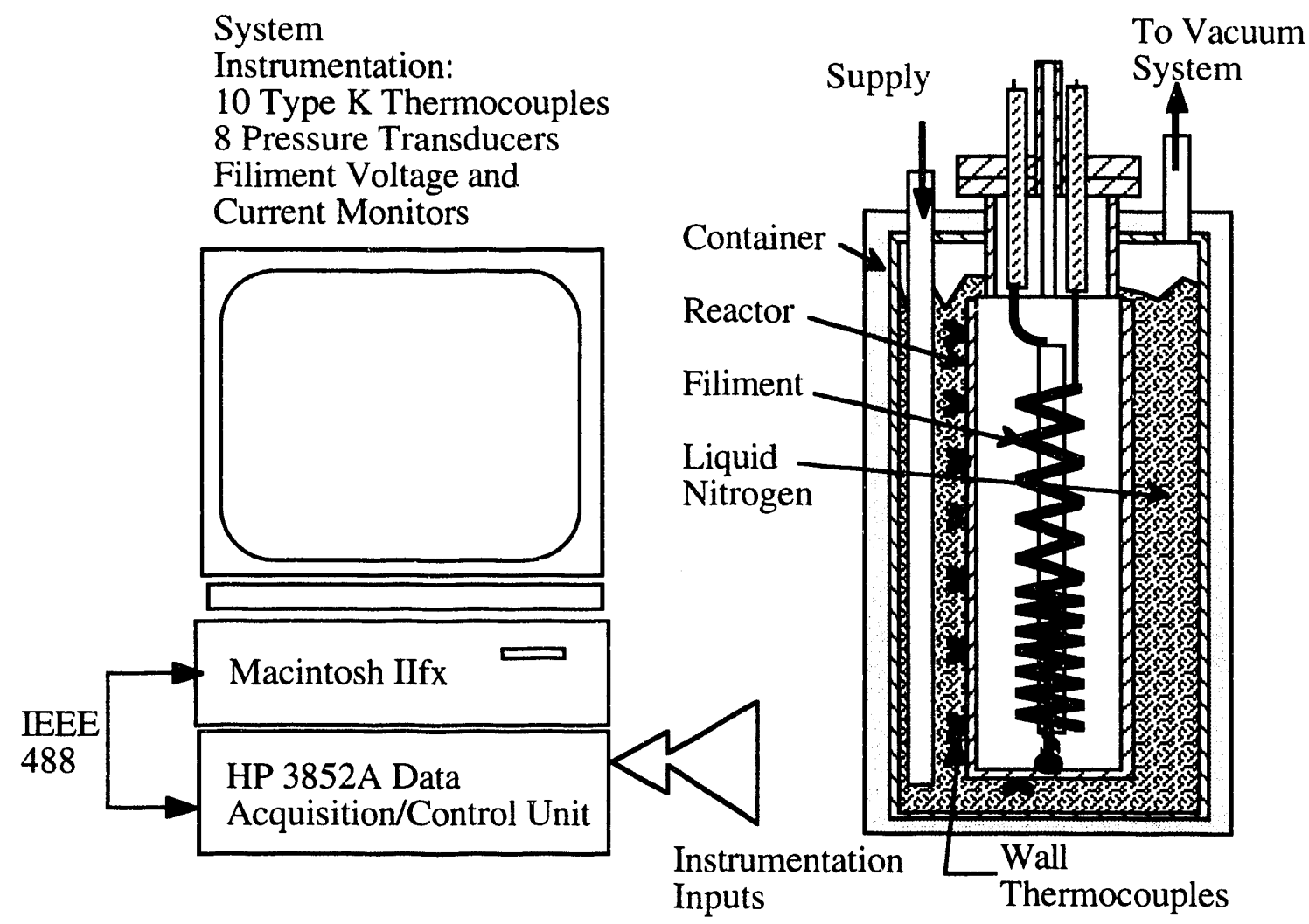

Figure 3. Instrumentation setup.

\section{CONTROLS}

Initially, an attempt was made to control the liquid nitrogen flow of the system by observing the temperature of a heated thermocouple, which was located at the desired level for the liquid nitrogen. However, the boiling was so violent that the liquid-gas interface could not be distinguished. In a second attempt, the thermocouples on the walls of the reactor vessel were used to indicate the liquid level, the effect on the wall temperatures from the manual change of liquid nitrogen flow was slow, and the response of the loading on the vacuum system was quick, making it difficult to control the liquid nitrogen level.

During the above runs, the vacuum pumps could only pump a limited volume of gas. The limiting pressure became 240 torr in the liquid nitrogen sealed Dewar and 80 torr in the ballast tank, see Figure $4 \mathrm{a}$. With a pressure of 80 torr in the ballast tank, the pumping speed was $65 \mathrm{~L} / \mathrm{s}$, and additional loading could not be handled by the vacuum system. Realizing that the container pressure was limited by the pumping speed, we adjusted the flow of liquid nitrogen to maintain a pressure in the container that the vacuum pumps could handle. The liquid flow was maintained by responding to the pressure changes in the container. The system maintainable at steady-state conditions. The experiments could then be controlled for sufficiently long periods of time, typically an hour, to examine the effects of the colder walls on the production rate of $\mathrm{KrF}_{2}$.

\section{TEST RESULTS}

Five production runs, using the lower pressure nitrogen boil-off, were conducted to evaluate the effect of lower wall temperature on the production rate in the synthesis of krypton difluoride. Figures $4 \mathrm{a}, \mathrm{b}$, and $\mathrm{c}$ shows the pressure in the container and ballast tanks, the typical wall-temperature profiles in the reactor, and the heat loads from the filament of the reactor, respectively. In the final analysis, the production rate was improved by an average of 1.8 times by reducing the cold-wall temperature by 6 to $8 \mathrm{~K}$.

Heat transfer analyses were done to estimate the temperature at which the reaction 

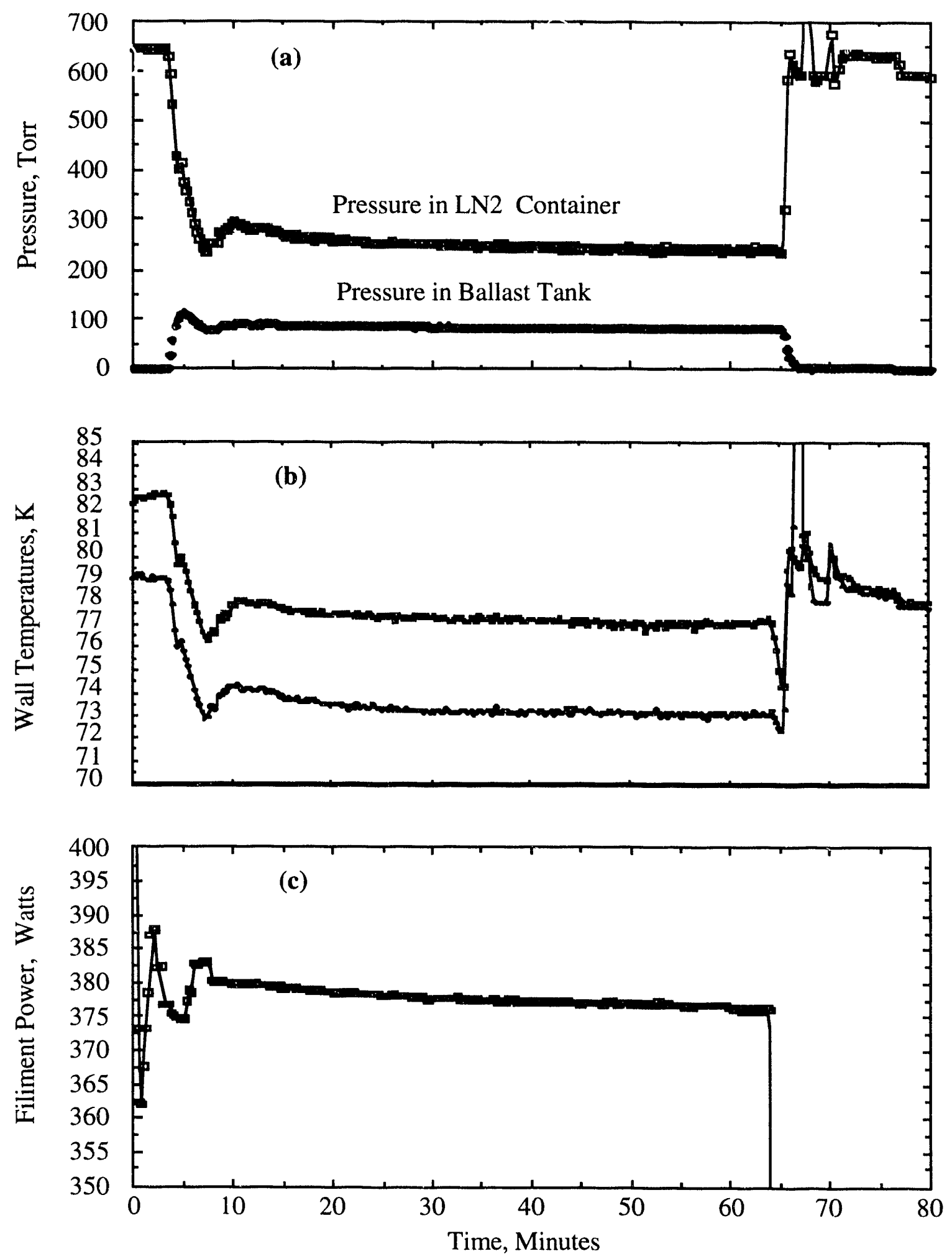

Figure 4. (a) Pressure in liquid nitrogen system. (b) Outside wall temperature in mid-area of reactor. (c) Filament Power. 
occurred (see Figure 5). Heat fluxes of 0.6 watts $/ \mathrm{cm}^{2}$ at the wall of the reactor produce a film, resulting in a temperature drop in the nucleate boiling of liquid nitrogen of $2.5 \mathrm{~K}$; additionally, a temperature drop occurs across the wall and across the solid krypton that is forming on the cold wall. For the liquid nitrogen at $78 \mathrm{~K}$, the estimated temperature at which reaction takes place is about $82 \mathrm{~K}$. When the pressure of the liquid nitrogen boil-off was reduced to $71.5 \mathrm{~K}$, the reaction temperature was $75.7 \mathrm{~K}$. The results of the analysis show that the magnitude of heat fluxes are significant, and the synthesis occurs at higher temperatures than were forecast.

\section{CONCLUSIONS}

The process of lowering the temperature of the liquid nitrogen worked well, and the effort necessary to accomplish this goal was within reason for examining the lower temperature effects; as predicted, Krypton difluoride was produced at an improved rate. Problems encountered with the vacuum system presented no obstacles in the accomplishment of the goal. It was found that the ballast tank was necessary, first to provide a volume to accept the gas loading that resulted from the transient condition of lowering the temperature of the liquid nitrogen, and second to provide a low enough inlet pressure for the vacuum rotary vane pumps to work. Additionally, the ballast tanks allowed the blow-by $\mathrm{LN}_{2}$ and nitrogen gas boil-off to warm up before the nitrogen was pumped through the vane pumps. The control, or balancing, of the vacuum system with the heat load, or gas generating, can be accomplished. The pressure/temperature desired in the liquid nitrogen can be established by the pumping rate of the vacuum system. The most effective method for maintaining constant reactor temperature was to adjust the flow of liquid into the system based on pressure control.

For our system, we were limited by pumping capacity, and by the large blow-by of $\mathrm{LN}_{2}$ that comes from the rapid depressurization and the large heat load. We estimate that at least half of the pumping requirements resulted from the blow-by from the $\mathrm{LN}_{2}$ container. We tried to maintain the level of the liquid nitrogen near the top of the reactor, which was very near the vapor exit orifice. Therefore, unless the $\mathrm{LN}_{2}$ blow-by is reduced, even the higher capacity pumps will not effectively reduce the temperature. Additionally, the heat analysis showed that there is a temperature gain across the Dewar interface, so one cannot expect to achieve the absolute temperature associated with an $\mathrm{LN}_{2}$ vapor pressure of 50 torr, $63 \mathrm{~K}$.
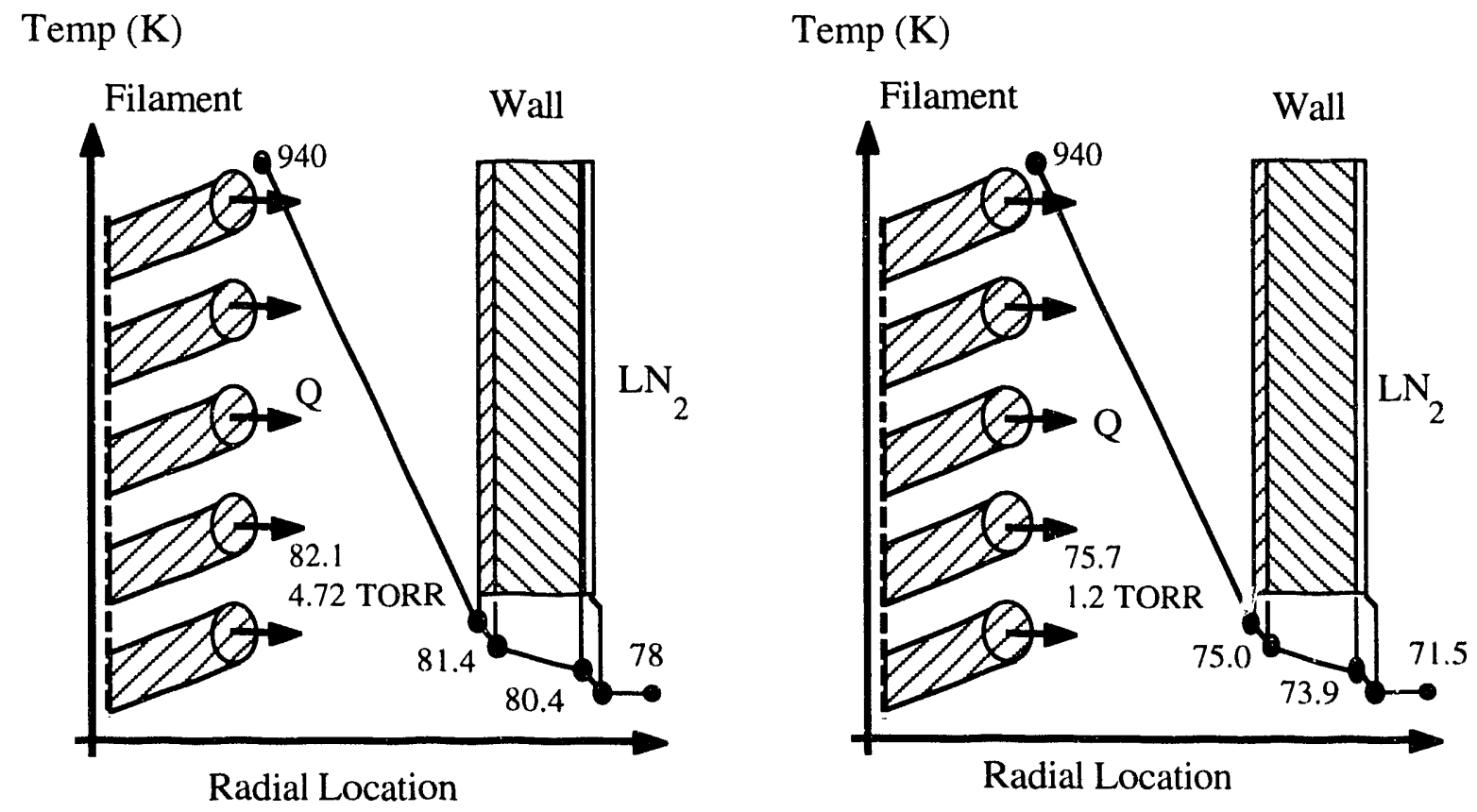

Figure 5. Calculated temperature profiles for atmospheric nitrogen and reduced pressure. 


\section{RECOMMENDATION}

The first recommendation is to use a simpler method of controlling $\mathrm{LN}_{2}$ pressure in the Dewar. It has been suggested that a mechanical device, referenced to the desired, pressure, could be easily used and built. ${ }^{4}$ Although the number of experiments we needed to run precluded the need for such a device, for longer term studies, or for a production device, this self-regulating pressure control would greatly ease synthesis.

Reduction in blow-by would enable the reduction of vapor pressure, and hence result in a lower attainable temperature. The exit orifice for the nitrogen on the Dewar was situated $5 \mathrm{~cm}$ above the desired liquid level. It would catch less agitation of the $\mathrm{LN}_{2}$ if it were placed $15 \mathrm{~cm}$ above the desired liquid level. A liquid-vapor separator made of porous material with a large surface area would be effective in reducing the of $\mathrm{LN}_{2}$ blow-by, if the pressure drop across the porous material was small.

\section{REFERENCES}

1. A system that would have a lower temperature than liquid atmospheric nitrogen $(78 \mathrm{~K})$ could have been used (liquid oxygen for example), but would have required a system redesign and more effort and extreme care in use and handling than simply lowering the vapor pressure of $\mathrm{LN}_{2}$. Also, a multistage refrigeration system or other systems could work, but would not have been as easy to implement into our system.

2. B.B. Chaivanov, V.B. Sokolov, S.N. Spirin, "Researches in the Field of Inorganic Fluorine Chemistry," I.V. Kurchatov Institute of Atomic Energy-Atominform, Moscow (1989).

3. V.N. Bezmel'nitsyn, V.A. Legasov, S.N. Spirin, and B.B. Chaivanov, Kinetics of the catalytic atomization of fluorine, Dokl. Akad. Nauk SSSR, 262:1153 (1982).

4. Thomas R. Mills, private communication . 

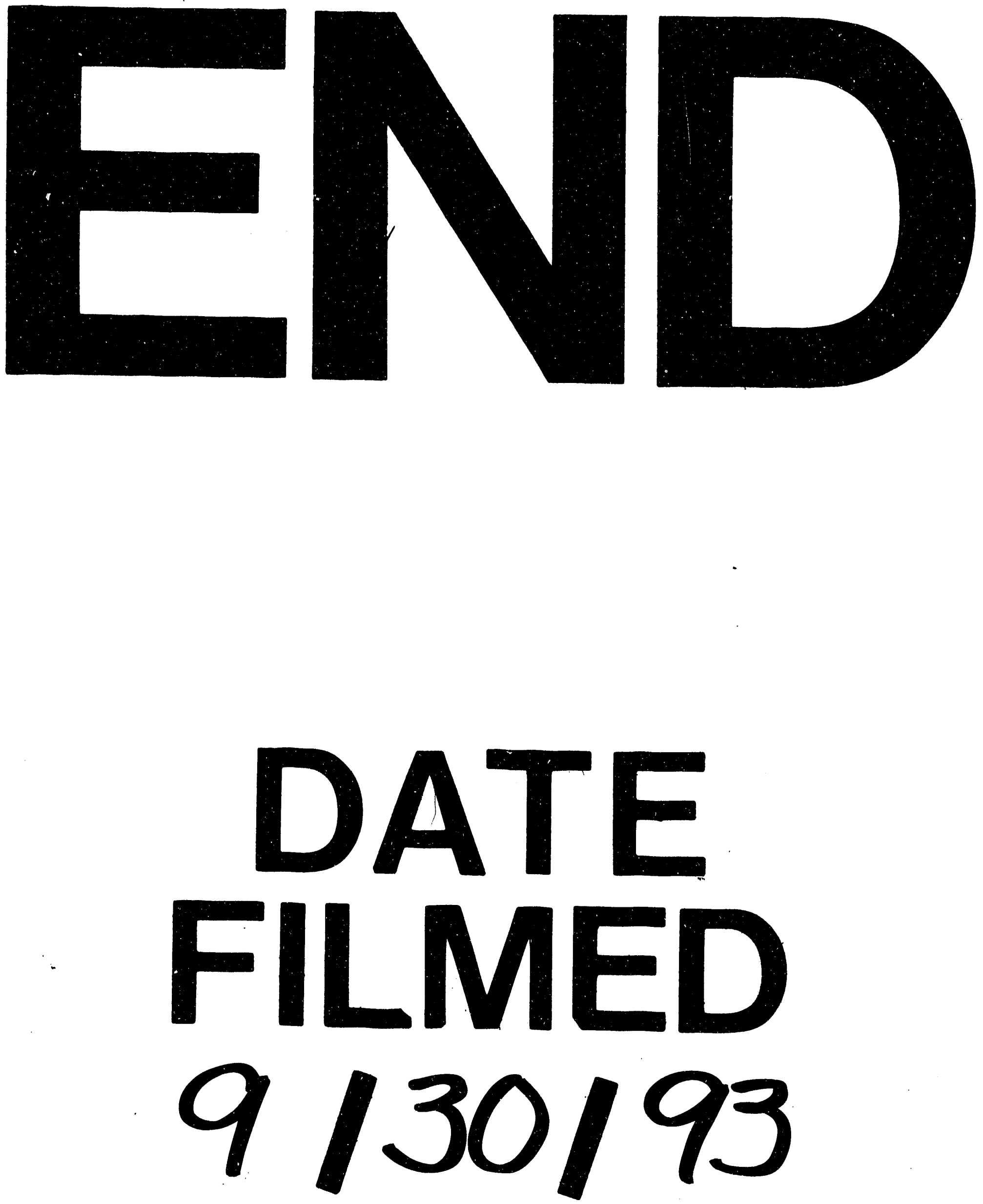
